\section{The first artificial pacemaker: the best thing since sliced bread?}

\author{
John Launer
}

If you had bought a copy of the American magazine 'Popular Mechanics' in March 1933, you would have seen the announcement of two remarkable new machines on the same page. ${ }^{1}$ One of these was an automated bread slicer. "Bread is cut and spread with butter or jam at the turn of a crank", the report explained. "It has a capacity of sixty slices a minute. The thickness of the slice and the spread can be regulated, and no special preparation of either the bread or the butter is necessary." The other, slightly longer report described a different crank-driven machine, under the heading "Beating of heart is revived by electrified needle." It gave an account of an apparatus called "the artificial pacemaker." "When the heart stops", the article reported, "the needle is inserted into the right auricle. Electrical impulses of low power are applied with a generator. These impulses can be regulated to forty, eight or 120 beats per minute, depending on the age of the patient and the normal rate of his heartbeat. Where the operation is successful, the electrical stimuli restore the inert heart to its natural beat".

The machine being described here was the one that the New York cardiologist Albert Hyman had announced the previous year in the Archives of Internal Medicine. ${ }^{2}$ It was there that he first introduced the term "artificial pacemaker", likening it to the heart's own natural pacemaker, the sinu-atrial node. Hyman considered the hand-operated electrical generator that he had invented (with his brother Charles) to be an advance on a method of cardiac resuscitation he had reported earlier - a simple needle thrust into the heart without any added chemical or electrical stimulus at all. ${ }^{3}$ "The introduced electric impulse"" he wrote concerning the new approach, "serves no other purpose than to provide a controllable irritable point from which a wave of excitation may arise normally and sweep over the heart along its accustomed pathway." Hyman's device is now generally acknowledged as the precursor of all pacemakers, although there are a number of questions surrounding its efficacy, which one historian has described as being "fraught with numerous controversies."

\section{QUESTION MARKS}

The first question mark regarding the Hymanotor (as it came to be called) is whether it should be categorised as a pacemaker at all. Setting aside its inevitable limitations compared with today's pacemakers, which are small, implantable, battery-driven and can function for a decade rather than a few minutes, many people would consider that should really fall under the heading of a defibrillator. Since the electricity was delivered to the right atrium, it could not have addressed the problem for which modern pacemakers are used, namely the treatment of complete atrio-ventricular block. If the device resuscitated patients who suffered cardiac arrest, it presumably would have done so by exactly the mode claimed by Hyman for his original method, namely by a physical insult to the myocardium, rather than by producing low voltage pulsations. It would of course be no mean achievement to be recognised as the originator of a separate lifesaving device. It would also not be Hyman's fault that his original label was applied to something else.
If the Hymanotor was in fact a defibrillator, was it effective? Hyman certainly claimed that it "could restore life in cases of sudden death from heart diseases like angina pectoris and coronary thrombosis" 5 although he never published reports of his clinical outcomes or laboratory experiments. He made three different versions of the machine, but none survived. A prototype made for production by the German company Siemans according to his instructions proved to be ineffective. (A company representative even declared the device a "plumper Schwindel" - a clumsy fraud.) Hyman claimed that his machine had produced extrasystoles shown on electrocardiography, but modern reanalysis of the tracings has not confirmed this. Scrutiny of all the available technical date on his three machines has led modern cardiologists to reach the conclusion that "output stimuli were long and of low amplitude and would probably have been unable to evoke a cardiac response in human beings. ${ }^{6}$ Any evidence that the machine actually worked must therefore be regarded as inconclusive at best. A battery-driven replica built in the 1990s on the basis of Hyman's patent application and diagrams looks splendid, like some Heath Robinson contraption, (see figure 1) but it was never clinically tested.

\section{TAMPERING WITH DIVINE PROVIDENCE}

At some point, Hyman quietly stopped promoting the device. Later in life, he attributed this to prejudice and abuse from the press, public and medical profession. $\mathrm{He}$ wrote a narrative of his recollections, and a

Figure 1 Replica of Hyman's "artificial pacemaker". (c) Technical Museum Vienna. 
physician called DC Schechter used this as the basis of a historical review. ${ }^{7}$ Schechter reported Hyman's claim that he had revived 14 out of 43 laboratory animals with the machine. He also described how the inventor "was beset with abusive correspondence, and even lawsuits, from irascible people who regarded his resuscitation endeavours as sacrilegious tampering with the Divine Providence." He lamented the medical profession's overwhelming suspicion of "gadgetry", but conceded that doctors had been bombarded with this at the time, as a result of poor regulation. In a subsequent article, Schechter also disclosed that Hyman claimed to have used the device successfully in several cases of complete heart block after all. ${ }^{8}$ This apparently included an incident of restoring consciousness to a man suffering a Stokes-Adams attack. If that was the case, the device would indeed have qualified as pacemaker in the modern sense, although the account contains inconsistencies regarding the timing and the people involved. ${ }^{6}$ In addition, Hyman and his colleagues had inserted the needle into the right atrium as before, which presumably could not have been effective if the diagnosis had been one of complete atrioventricular block.

There is nothing in the literature to support any inference that Albert Hyman was a fraudster. On the contrary, there is much to suggest he was a conscientious and decent physician. The likeliest interpretation of these events is that he had a blind spot about his 'brainchild.' This may have led him to misinterpret clinical events, ignore disconfirmation of his conclusions, and unconsciously reconstruct his memories. These are common failings among doctors. and it is not hard to feel empathy for him if that was the case. It is also possible that he reacted to hostility by abandoning his project, even if this was partly a pretext. To his credit, Hyman correctly anticipated that electricity might successfully reverse cessation of the heartbeat - but there was, insufficient knowledge in the 1930s of the various causes of this, or of the differences in voltage, site, frequency and supplementary therapy that might be required as a result.

Hyman's “artificial pacemaker” continues to have a prominent place in histories of medical technology - and it is probably fair that it does. Scientific progress does not move smoothly from concept to success; there are false starts and failures before something of lasting benefit is discovered. Hyman's own machines may never have been successful, but it was not long afterwards that that Wilfred Bigelow, Paul Zoll, Earl Bakken and others introduced devices that really did function as pacemakers. ${ }^{9}$ For all we know, the machine for slicing bread and spreading butter or jam on it may also not have been quite as good as its inventors hoped, but it no doubt led on to more advanced versions that did the job perfectly.

Twitter Follow John Launer @JohnLauner

Competing interests None declared.
Provenance and peer review Commissioned: internally peer reviewed.

(C) Article author(s) (or their employer(s) unless otherwise stated in the text of the article) 2017. All rights reserved. No commercial use is permitted unless otherwise expressly granted.

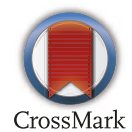

To cite Launer J. Postgrad Med J 2017;93:715-716.

Postgrad Med J 2017;93:715-716.

doi:10.1136/postgradmedj-2017-135368

\section{REFERENCES}

1 Beating of heart is revived by electrified needle. In: Popular Mechanics, 1933:360. https://goo.gl/FDW37f (accessed 27 Sep 2017).

2 Hyman AS. Resuscitation of the stopped heart by intracardial therapy II. experimental use of an artificial pacemaker. Arch Intern Med 1932;50:283-305.

3 Hyman AS. Resuscitation of the stopped heart by intracardial therapy. Arch Intern Med 1930;46:553-68.

4 Mittal T. Pacemakers - a journey through the years. Indian J Thorac Cardiovasc Surg 2005;21:236-49.

5 Electric 'starter' for heart shown. New York Times, 11 February 1936

6 Furman S, Jeffrey K, Szarka G. The mysterious fate of Hyman's pacemaker. Pacing Clin Electrophysiol 2001;24:1126-37.

7 Schechter DC. Background of clinical cardiac electrostimulation, V: direct stimulation of heart without thoracotomy. NY State J Med 1972;72:605-19.

8 Schechter DC. Background of clinical cardiac electrostimulation. VI. precursor apparatus and events to the electrical treatment of complete heart block. NY State J Med 1972;72:953-61.

9 Aquilina O. A brief history of cardiac pacing. Images Paediatr Cardiol 2006;8:17-81. 